Research Article

\title{
Prediction of the Progressive Loss of Winding Clamping Pressure in Power Transformers
}

\author{
Shuguo Gao $\mathbb{D}$, Jun Zhao, Lingming Meng, and Hongliang Liu
}

State Grid Hebei Electric Power Research Institute, Shijiazhuang 050021, China

Correspondence should be addressed to Shuguo Gao; 15830105382@139.com

Received 22 July 2019; Accepted 13 January 2020; Published 18 February 2020

Academic Editor: Nhon Nguyen-Thanh

Copyright (C) 2020 Shuguo Gao et al. This is an open access article distributed under the Creative Commons Attribution License, which permits unrestricted use, distribution, and reproduction in any medium, provided the original work is properly cited.

\begin{abstract}
This paper investigates the progressive loss of winding clamping pressure resulted from thermal aging in power transformers. Firstly, out-of-plane stress-strain characteristics of aging pressboards are investigated experimentally and relationship between mechanical properties of pressboards and aging hours is established accordingly. Then, a thermal-mechanical model is built to correlate the aging time with temperature based on the first-order reaction kinetics. Based on the above investigations, the correlation between temperature and mechanical properties of pressboards is obtained and the progressive loss of clamping pressure is predicted. The results show that with the progressive softening of pressboards from aging, the clamping pressure drops linearly under $60^{\circ} \mathrm{C}$ and nonlinearly over $60^{\circ} \mathrm{C}$. The remaining clamping pressure of a transformer winding with 30 years' service history is only $80.12 \%$ and $51.59 \%$ of its initial pressure under $50^{\circ} \mathrm{C}$ and $60^{\circ} \mathrm{C}$, respectively.
\end{abstract}

\section{Introduction}

The winding clamping pressure, determining natural frequencies of windings and providing support to winding radial structures, has a significant impact on withstand ability to short circuits of windings [1]. However, the initially applied clamping pressure can be affected by temperature, moisture, and aging [2]. Among these influencing factors, the temperature-based expansion and moisture-based expansion have a temporary influence, while the aging makes a permanent change in the insulation material as well as the clamping pressure [3]. Hence, it is necessary to predict the progressive loss of clamping pressure of transformer windings for assessing its ability to withstand short circuits.

Pressboards, constituting spacers and bearing the outof-plane compressive load, are composed of paper sheets [4]. Influenced by cellulose degradation and fracture, mechanical properties of pressboards can also be affected. Previous studies mainly concentrated on investigating reaction kinetics of aging over temperature and moisture, establishing the relationship between the tensile strength and the degree of polymerization (DP), and evaluating the aged insulation paper through various kinds of methods [5-9]. The first-order and the second-order kinetic equations were established to correlate the reaction kinetics and DP $[5,6]$. Analysis of the relationship between DP and tensile strength found that the tensile strength of the insulation paper was critically dependent on the DP of cellulose. The lifetime of insulation paper and power transformers under different temperatures could be estimated through a differential equation of the wide-span and zero-span tensile strength versus DP value [7]. These research studies are impressive to reveal the degradation mechanism in cellulose and the relationship between mechanical properties and the DP value of the insulation paper.

Investigations on mechanical properties of pressboards mainly focused on analyzing the out-of-plane mechanical properties and characterizing its mechanical behaviour. A continuum material model was established to simulate responses of pressboards subjected to stationary and transient loads $[10,11]$. An elastic-plastic material model for the outof-plane mechanical behaviour of paper was proposed by Stenberg [12]. Naranpanawe investigated the stress-strain characteristics of aging pressboards [13]. But he did not establish a specific model for characterizing and predicting the progressive loss of clamping pressure. So far, there is still a lack of the relationship between the out-of-plane 
mechanical properties of aging pressboards and the prediction of clamping pressure over transformers' service life.

This paper proposes a model to predict the progressive loss of clamping pressure over the operating time and temperature. The out-of-plane compressive characteristics are tested on stacked pressboards. These pressboards were obtained through the accelerated aging experiment with different aging hours. The DP of aging pressboards is measured to establish the thermal-mechanical relationship between mechanical properties and reaction kinetics of cellulose. Finally, a prediction model of clamping pressure embedding with the operating time and temperature is established.

\section{A Brief Introduction on the Structure of Pressboards and Its Impact on Winding Clamping Pressure}

2.1. Manufacturing and Structure of Pressboards. Electrical pressboards are mostly made from wood pulp processed by the Kraft chemical process [4]. In manufacturing, the wood is dissolved in the sulfate to reduce the percentage of lignin and obtain fined celluloses. Then, the wood pulp is fed on to moving mesh (machine direction (MD)) belts on revolving drums to let the water be absorbed by suction pumps. After forming paper sheets in the cylinder pressing process, multiple sheets may be calendered or compressed to form denser and stronger pressboards [4].

Due to the special manufacturing process, the actual structure of pressboards is composed of several layers of paper sheets, as shown in Figure 1. Between these sheets, few cellulose fibers are connected, while in the paper (in-plane), lots of cellulose chains are bonded together. The spatial arrangement of fibers in the network leads to anisotropy between the out-of-plane direction (thickness direction) and inplane direction. Experiments demonstrate that the strength in the machine direction (MD) and cross-machine direction (CD) is about 100 times and 10 times higher than that of the out-of-plane direction [12]. The out-of-plane mechanical properties are determined by the weak connection between fiber chains.

2.2. Relationship between Clamping Pressure and Out-ofPlane Characteristics of Pressboards. Since pressboards are clamped between winding disks and the pressure acts in the out-of-plane direction, the clamping pressure is closely related to their out-of-plane stiffness. In manufacturing, windings will go through the drying, sizing and stabilizing, and retightening process before tassembling with the core [1]. After that, to maintain enough ability to withstand short circuits, a clamping system is utilized to compress windings to the specified preload value [13].

Along the axial direction of windings, the whole winding is an elastic system where pressboards and conductors can be viewed as series-connected springs. The stiffness $K_{s}$ of one spacer which is stacked by several pressboards is [1]

$$
K_{s}=\frac{A}{h} \times \frac{\sigma}{\varepsilon}=\frac{A}{h} \times E,
$$

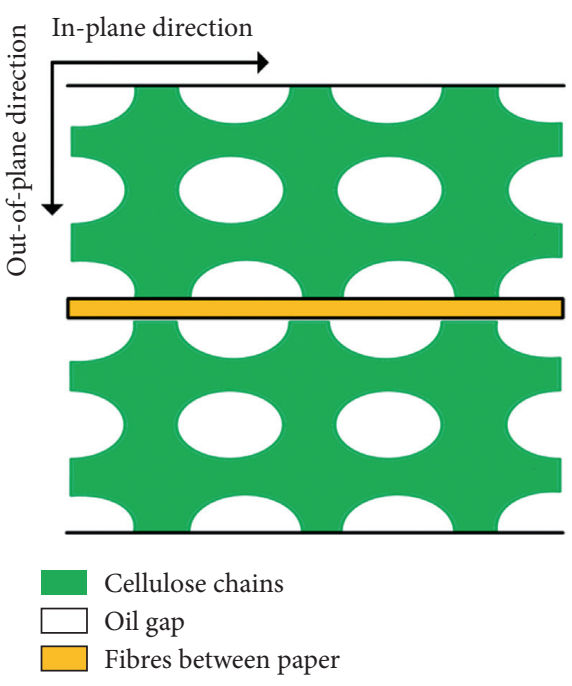

FIGURE 1: In-plane and out-of-plane structures of pressboards.

where $K_{s}$ is the stiffness of one spacer, $A$ is the contact area between pressboards and conductors (also the areas of spacer), and $h$ is the thickness of one spacer (stacked pressboards).

The stiffness of the overall winding is the stiffness of the series-connected stacked spacers and conductors, which is

$$
\frac{1}{K}=\left(\frac{n_{1}}{m K_{s}}+\frac{n_{2}}{K_{c}}\right),
$$

where $K$ is the stiffness of the winding. $n_{1}$ and $n_{2}$ are the number of one column spacer in the axial direction and winding disks, respectively. $m$ is the number of circumferentially placed spacers between two winding disks. $K_{s}$ and $K_{c}$ are the stiffness of one spacer and conductors in one winding disk, respectively.

Through (2), the winding compaction $\xi$ under the applied clamping pressure $F$ excluding the gravity is obtained:

$$
\xi=\frac{F}{K}=F\left(\frac{n_{1}}{m K_{s}}+\frac{n_{2}}{K_{c}}\right) .
$$

Since the stiffness of conductors is much higher than that of pressboards, the compaction is mainly determined by the soft insulation material. Hence, equation (3) can be simplified into

$$
\xi \approx \frac{F n_{1}}{m K_{s}}=\frac{F n_{1} h}{m A E} .
$$

Because of the rigid clamping system (e.g., clamping frame, rods, and tie bars), the compaction displacement of windings during the whole operation life remains unchanged. Therefore, the clamping pressure $F$ is proportional to the elastic modulus of pressboards based on equation (4).

\section{Out-of-Plane Stress-Strain Characteristics of Aging Pressboards}

As a cellulose-based and porous material, the cellulose chains in the insulation paper can degrade into short and 
weak chains and consequently reduce pressboards' mechanical properties. This section presents the accelerated aging experiments on pressboards, the measurement on the out-of-plane compressive characteristics of aging pressboards, and the relationship between mechanical properties and aging time.

3.1. Accelerated Aging Experiment. The accelerated aging experiment was carried out on high-density pressboards (density between 1.00 and $1.20 \mathrm{~g} / \mathrm{cm}^{3}$ ) to obtain aging samples. In the preprocessing procedure, the moisture content in the oil and pressboards needs to be eliminated. Several pieces of pressboards, whose thickness was $1.5 \mathrm{~mm}$ $( \pm 7.5 \%)$, were cut into almost squared samples $(30 \mathrm{~mm} \times 29 \mathrm{~mm})$. Then, these samples and the transformer oil were separately placed in a vacuum drying oven to reduce moisture at $120^{\circ} \mathrm{C}$ for 48 hours. After that, the dry pressboards and the degassed transformer oil were mixed in a glass beaker and placed in a vacuum oven at $25^{\circ} \mathrm{C}$ for 48 hours to obtain the fully oil-impregnated pressboards.

After the above procedures, the samples and the oil were conducted in an accelerated aging experiment. The temperature of the oven was set at $120^{\circ} \mathrm{C}\left( \pm 2^{\circ} \mathrm{C}\right)$ with $0.105 \mathrm{MPa}$ nitrogen working as the shielding gas. The reason to conduct the experiment under $120^{\circ} \mathrm{C}$ is that the aging mechanism changes significantly when the temperature is over $140^{\circ} \mathrm{C}$, beyond which the activation energy increases apparently, and the gas evolves [14].

The whole accelerated aging experiment was carried out for 800 hours. During the experiment, four pieces of pressboards were taken out every 48 hours, except the pressboards at the 48th hour, 148th hour, and 388th hour. Then, pressboards were cooled down to $25^{\circ} \mathrm{C}$ for 24 hours in another vacuum oven to be prepared for the mechanical tests. Comparing the accelerated aging temperature at $120^{\circ} \mathrm{C}$, the influence of cooling temperature and duration on mechanical properties could be ignored.

3.2. Compressive Stress-Strain Measurements of Pressboards. The hydraulic measuring system MTS 858 was used to measure the stress-strain characteristics of pressboards, as shown in Figure 2(a). The grippers were surrounded by an attemperator and humidity controller, as shown in Figure 2(b). Considering the influence of oil on elastic modulus and the individual variation of each pressboard, four pieces of pressboard (total thickness $6 \mathrm{~mm}$ ) were placed on the central bottom of the cylindrical metal container that was filled with new degassed transformer oil and placed on the lower gripper, as shown in Figure 2(c).

An appropriate load should be chosen carefully to be applied to pressboards to obtain the stress-strain characteristics of pressboards. In [10,15], an alternating cyclic load is applied to pressboards. The applied maximum amplitude of the stress in the two papers is $20 \mathrm{MPa}$ and $60 \mathrm{MPa}$, respectively. However, in most cases, a clamping pressure between $2.5 \mathrm{MPa}$ and $3.5 \mathrm{MPa}$ is suggested by the manufacturer [16]. This is because a low clamping pressure cannot guarantee a sufficient prestress value during the operation, while the excessive pressure may result in an overextrusion in the insulation paper and damage the insulation paper. On the other hand, excessive clamping forces may also increase the possibility of conductor tilting. To overcome these limitations, a triangle-shaped cyclic load, ranging from $0.02 \mathrm{MPa}$ to $5 \mathrm{MPa}$ at $2 \mathrm{~Hz}$, is applied to pressboards. The cyclic load increases from $0.02 \mathrm{MPa}$ to $5 \mathrm{MPa}$ and then drops to $0.02 \mathrm{MPa}$ linearly. Eleven cycles were applied to the stacked pressboards to make the samples densified and stable in stress-strain conditions [9].

\subsection{Stress-Strain Characteristics of Aging Pressboards.} During the cyclic load, spacers between the fiber network are reduced and the connection between fibers is strengthened; consequently, pressboards were densified. Similar to the typical stress and strain under cyclic loads in [15], huge plastic deformation occurs after the first load cycle. During the following 10 cycles, the plastic deformation and the residual deformation caused by viscoelasticity decrease gradually. Consequently, the thickness of pressboards is gradually reduced and the mechanical properties of pressboards are gradually stabilized.

The obtained strain-stress characteristics of different aging pressboards in the last compression load are shown in Figure 3. For each curve, the stress increases sharply with the increasing strain. In addition to the obvious nonlinear stress-strain characteristics, the compressibility of pressboards increases with the increasing aging degree. The maximum strain under $5 \mathrm{MPa}$ is shown in Table 1 . The maximum strain increases from $2.90 \%$ of new pressboards to $5.54 \%$ of 800 -hour aging pressboards. It can be found that pressboards are getting compressible when they are degraded.

The increasing compressibility of pressboards is mainly caused by the change of structure in pressboards. In the outof-plane direction, the cellulosic structure is cross-linked with thin-wall fiber and inner voids. The collapsed fiber walls are assumed to be bonded to one another in the lumen, giving rise to a laminated structure [17]. The cell wall, the existence of damaged zones in the cell wall, and the network of hydrogen bonds also affect the strength. During degradation, the polymer cellulosic chains fracture or hydrolyze from original long and strong chains breaking into short ones. Therefore, the chains have more holes than new pressboards. Meanwhile, the hydrogen bonds also hydrolyze to weaken the bonding forces between fibers. These two reasons lead to the decreasing stiffness and embrittlement of fibers, particularly in the amorphous regions between areas of high crystallinity [13].

To further verify the influence of aging on the microstructure of pressboards, scanning electron microscopy (SEM) is utilized. The results of the 100-hour, 242-hour and 676-hour aging pressboards are shown in Figure 4. In the 100 -hour sample, the surface is relatively smooth and gaps between cellulose walls are filled with small fibers. Affected by the fracture of cellulose chains in the aging process, more and more strong fibers are isolated and the surface becomes 


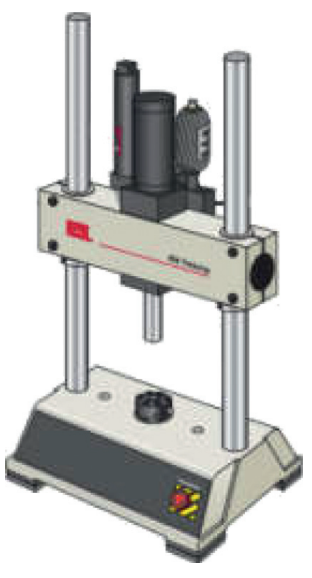

(a)

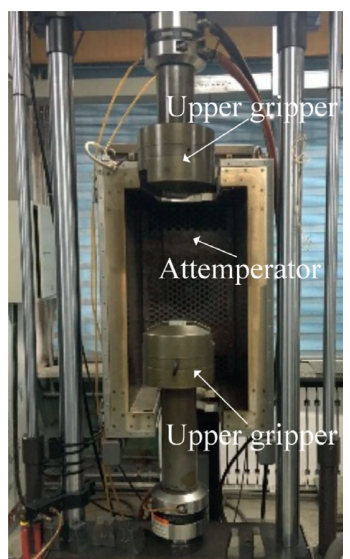

(b)

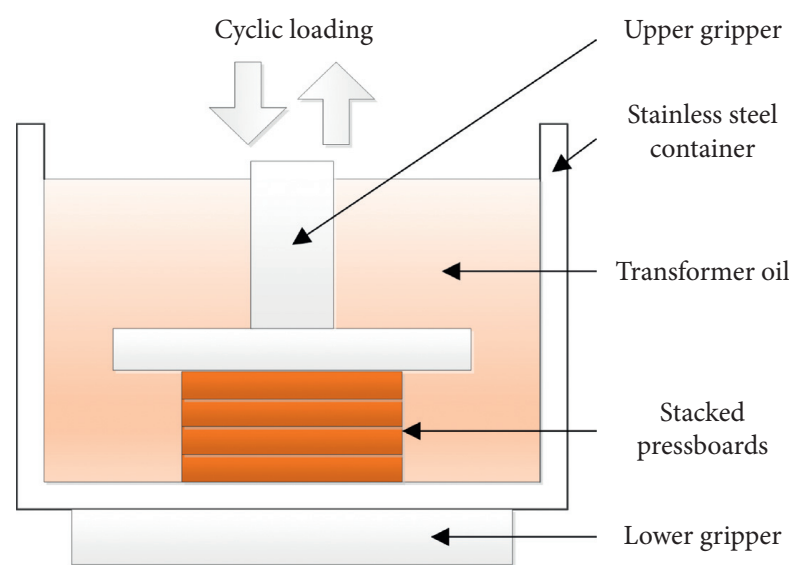

(c)

FIgURE 2: Experimental setup for stress-strain measurement. (a) MTS 858. (b) Attemperator and humidity controller. (c) Cylindrical metal container and stacked pressboards.

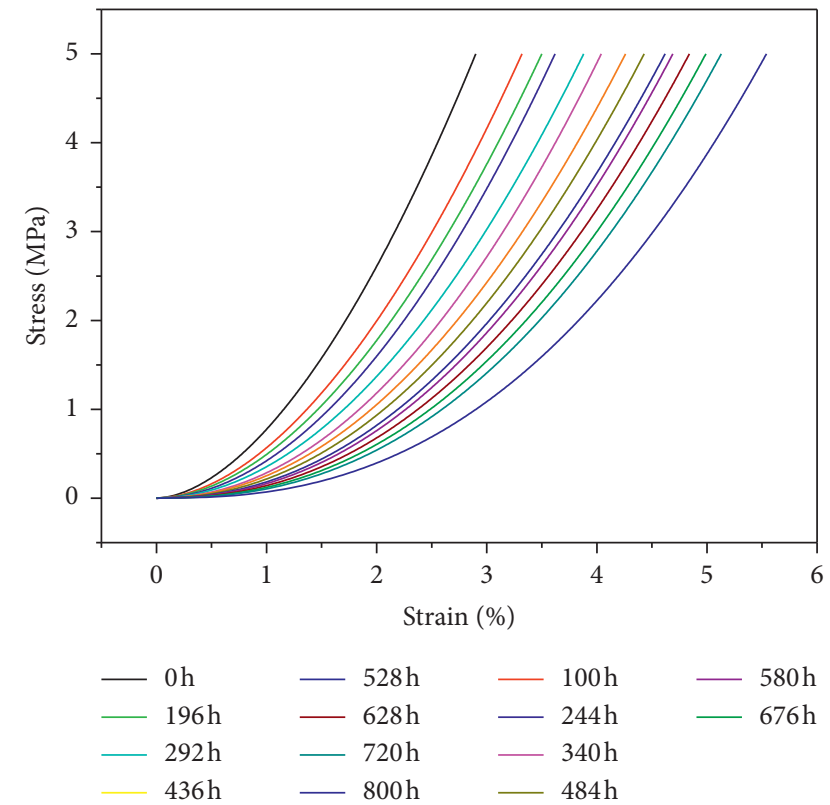

FIGURE 3: Stress-strain characteristics of degraded pressboard.

TABLE 1: Maximum strain under $5 \mathrm{MPa}$ of aging pressboards.

\begin{tabular}{lccc}
\hline Aging hour & Strain $(\%)$ & Aging hour & Strain $(\%)$ \\
\hline 0 & 2.90 & 100 & 3.32 \\
196 & 3.50 & 244 & 3.62 \\
292 & 3.88 & 340 & 4.04 \\
436 & 4.26 & 484 & 4.43 \\
528 & 4.62 & 580 & 4.69 \\
628 & 4.84 & 676 & 4.99 \\
720 & 5.13 & 800 & 5.54 \\
\hline
\end{tabular}

bumpy. In the 676-hour sample, most of the fibers break into short pieces and the connection between cellulose chains disappeared. The SEM results give a visual explanation that the decreasing number and the weakening size of fibers are the reasons for the decreasing stiffness of aging pressboards.
3.4. Relationship between Mechanical Properties and Aging Time. Although a continuum material model with viscoelasticity and plasticity is precise to illustrate the mechanical properties of aging pressboards, the description through polynomial or power function on stress-strain characteristics is more convenient and userfriendly for practical engineering use $[18,19]$. In this paper, the power function presented in [19] is adopted. The relationship between stress and strain under $5 \mathrm{MPa}$ is defined as

$$
\sigma=a \times \varepsilon^{b},
$$

where $\sigma$ and $\varepsilon$ are the stress and strain, respectively. $a$ and $b$ denote the constant related to the mechanical properties.

Equation (5) was applied to fit the stress-strain data in Figure 3. The obtained variables $a$ and $b$ are shown in Figure 5 . The variable $a$ shows a nonlinear increase with the increasing aging hour, and the variable $b$ shows an almost linear trend. To further establish the relationship between aging time and mechanical properties, $a$ and $b$ can be expressed as aging-time-dependent functions. Parameters are estimated through the least-mean-square regression algorithm. With the above parameters, mechanical properties of pressboards over aging time can be obtained. The regression model and the fitting goodness are shown in Table 2. The fitting goodness of the two variables exceeds 0.9 . It can be observed that variables $a$ and $b$ are suitable to be presented in an exponential model and a linear model, respectively.

According to the regression results in Table 2, (5) can be rewritten as

$$
\sigma=\left(314.84 \times e^{(t / 300)}+2094.34\right) \times \varepsilon^{\left(8.8529 \times 10^{-4} t+1.7132\right)} .
$$

Equation (6) is the relationship between the aging time and mechanical properties under $120^{\circ} \mathrm{C}$. The corresponding static elastic modulus is 


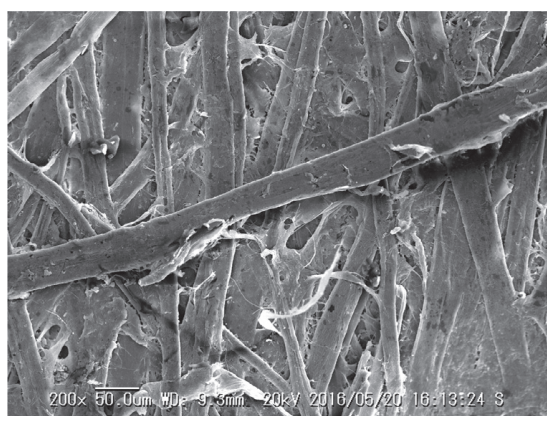

(a)

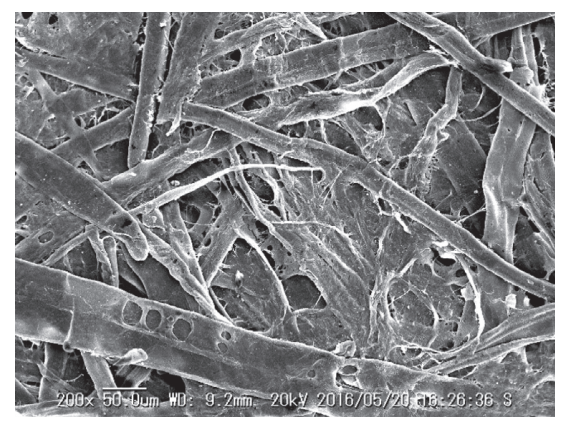

(b)

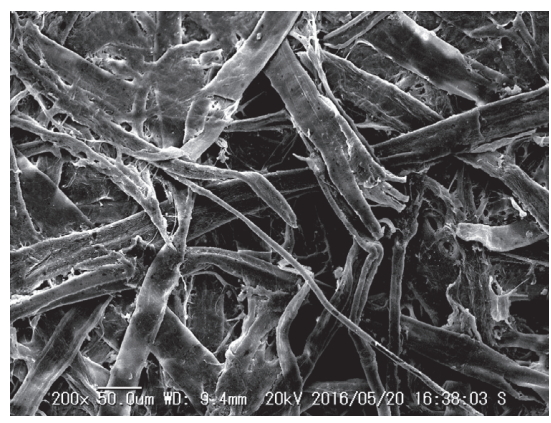

(c)

FIGURE 4: SEM results of the aging pressboard (the viewing filed is $200 \times 50 \mu \mathrm{m}$ ). (a) 100-hour sample. (b) 242-hour sample. (c) 676-hour sample.

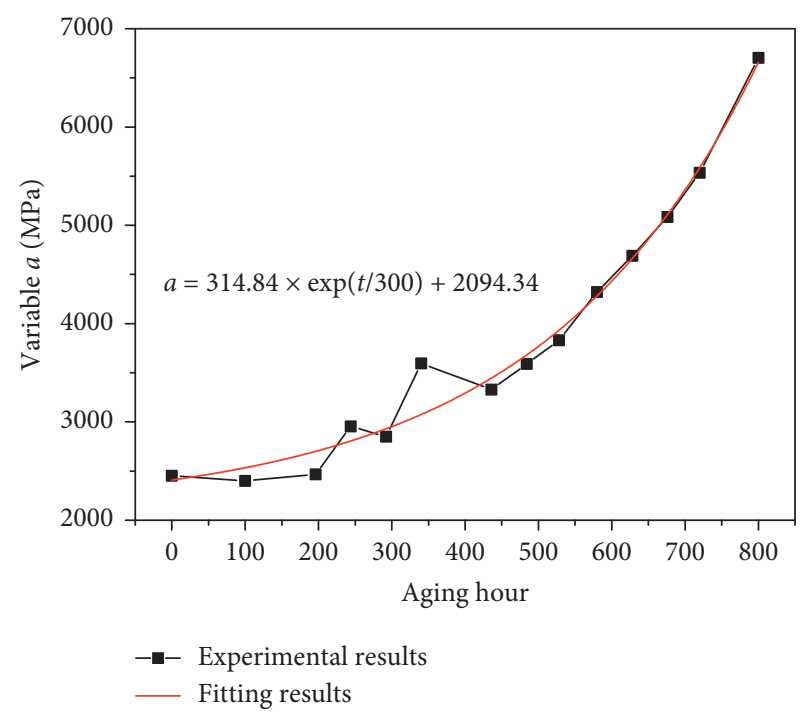

(a)

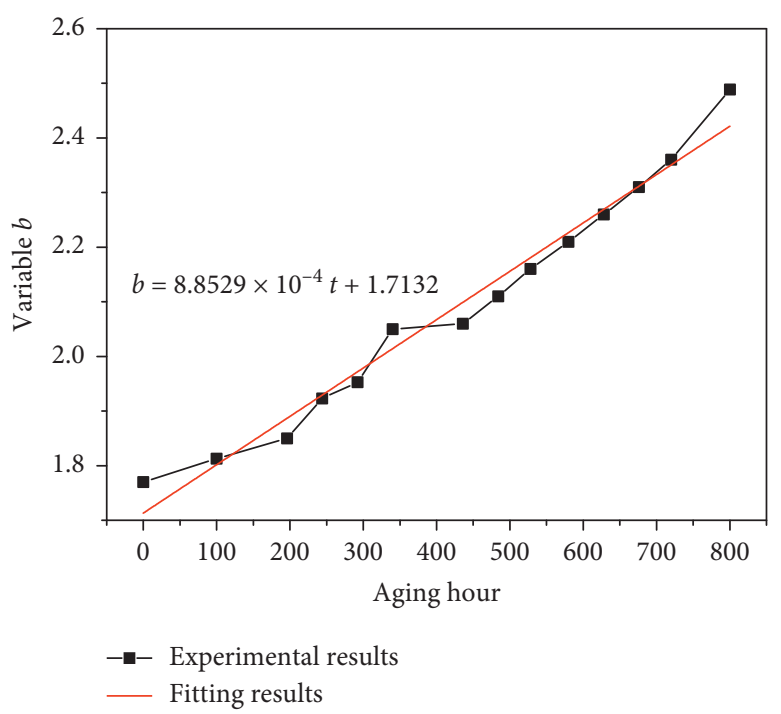

(b)

Figure 5: (a) The relationship between $a$ and aging time. (b) The relationship between $b$ and aging time.

TABLE 2: Fitting goodness of parameters $a$ and $b$.

\begin{tabular}{lcc}
\hline Parameters & Regression model & $R^{2}$ \\
\hline$A$ & $y=a_{3} x^{3}+a_{2} x^{2}+a_{1} x+a_{0}$ & 0.94479 \\
$B$ & $y=a e^{x}+a_{0}$ & 0.9773 \\
& $y=a x+a_{0}$ & 0.9747 \\
\hline
\end{tabular}

$E=\frac{\sigma}{\varepsilon}=\left(314.84 \times e^{(t / 300)}+2094.34\right) \times \varepsilon^{\left(8.8529 \times 10^{-4} t+0.7132\right)}$.

The elastic modulus over aging time and strain calculated from (7) is shown in Figure 6. It can be seen that the elastic modulus of new pressboards increases nonlinearly from $81.2 \mathrm{MPa}$ at the $0.2 \%$ strain to $227.48 \mathrm{MPa}$ at the $5 \%$ strain. When pressboards degrade, their elastic modulus decreases gradually. The elastic modulus of the 800-hour sample decreases significantly from the initial $227.48 \mathrm{MPa}$ to $94.79 \mathrm{MPa}$ at $5 \%$ strain.

\section{A Thermal-Mechanical Model of the Out-of- Plane Stress-Strain Characteristics of Pressboards}

In the previous section, out-of-plane stress-strain characteristics of aging pressboards are investigated and a power function model with two aging time-dependent variables is used to establish the relationship between aging time and mechanical properties. However, the obtained relationship is based on the results of the accelerated aging experimental under $120^{\circ} \mathrm{C}$. It cannot be applied to other operating temperatures. A possible solution is to find an intermediate quantity that can connect the mechanical properties under $120^{\circ} \mathrm{C}$ and other temperatures. The degree of polymerization (DP) is the suitable intermediate quantity.

This section presents measurement results on the DP value of aging pressboards and the establishment of a thermal-mechanical model to correlate the aging temperature to mechanical properties of pressboards. The proposed 


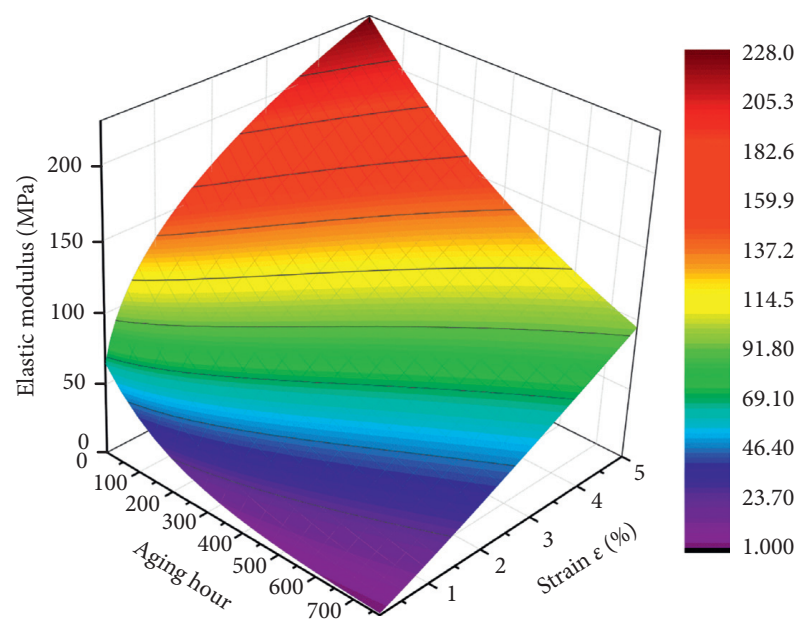

FIGURE 6: Relationship between elastic modulus, aging hour, and strain.

model is applied to predict the progressive loss of clamping pressure due to thermal aging.

4.1. Degree of Polymerization of Aging Pressboards. Cellulose, the component of paper and pressboard, is a polymer of glucose units linked to one another. It can be represented simply as $\left[\mathrm{C}_{5} \mathrm{H}_{10} \mathrm{O}_{5}\right]_{n}$, ignoring the extra atoms on the end groups, where $n$ is the value of DP [8]. The DP is an important indicator for assessing the aging degree of cellulosic material since it is related to the aging time and temperature. For the new insulation paper, its DP is between 1000 and 1200 . The drying process reduces the DP to the value between 850 and 950 [20]. The aging and other stresses in service reduce it further. The DP of new pressboards and the pressboards after the drying process is regarded as the same as that of the corresponding insulation paper.

The DP of aging pressboards was tested in another experiment according to the IEC standard [21]. The aging samples were processed in the same procedures as the pressboards in the accelerated aging experiment and mechanical test. The only difference was the sampling interval, which was 60 hours in DP measurement.

The measured DP value of the aging pressboards is shown in Figure 7 (black dot and curve). It can be observed that the DP of new pressboards is 775, which is slightly lower than the assumed value between 850 and 950. The difference may be due to the drying temperature used in this paper is a bit higher and 48 hours drying process leads to a certain degree of aging. The DP of pressboards decreases with the increasing aging time. The DP of 720-hour aging pressboards is only $28.39 \%$ of the initial DP value.

Considering the temperature around pressboards should be lower than that around the paper, the aging in pressboards should not be obvious than that of the paper around the hot spot in windings. The DP could change within a small range and maintain a higher value. Hence, the firstorder model of the kinetics of cellulose scission is accurate

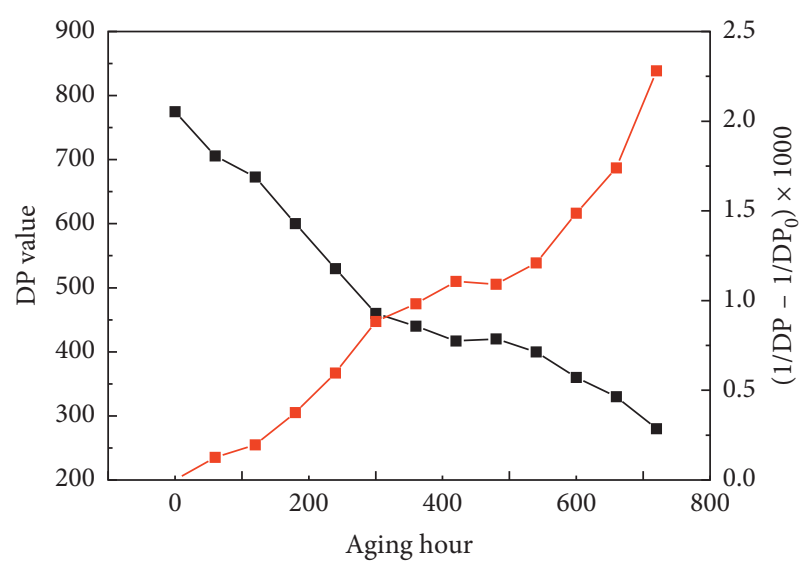

FIgURE 7: Relationship between DP value and aging hour.

enough to express the reaction kinetics of scission when the DP is above 200. The expression of the first-order model is

$$
\frac{1}{\mathrm{DP}_{t}}-\frac{1}{\mathrm{DP}_{0}}=k t
$$

where $\mathrm{DP}_{t}$ and $\mathrm{DP}_{0}$ are the number-average degree of polymerization at the aging time $t$ and the start (initial state). $k$ is the reaction rate constant whose value depends on the temperature.

The $1 / \mathrm{DP}-1 / \mathrm{DP}_{0}$ curve (red dot and curve) is also shown in Figure 7. It increases almost linearly when DP is higher than 400. When DP is between 400 and 200, the curve increases dramatically. The value of DP is fitted according to (8), and obtained $k$ is $2.6369 \times 10^{-6}$ under $120^{\circ} \mathrm{C}$ (fitting goodness $R^{2}=0.9654$ ).

The reaction rate $k$ is determined by the temperature and follows the Arrhenius equation, as follows:

$$
k=A \cdot \exp \left(-\frac{E_{a}}{R(T+273)}\right),
$$

where $A$ and $E_{a}$ represent the apparent frequency factor and activation energy of the multiple reaction system, $R$ is the gas constant $(8.314 \mathrm{~J} /(\mathrm{mol} \cdot \mathrm{K}))$, and $T$ is the reaction temperature in Celsius.

The preexponential constant $A$ is between $2.41 \times 10^{7}$ and $4.71 \times 10^{8}$ with $95 \%$ confidence for the dry Kraft paper in oil [20]. Thus, the activation energy $E_{a}$ for pressboard degradation can be estimated through (9). The calculated $E_{a}$ is between 96 and $108 \mathrm{~kJ} / \mathrm{mol}$, which is reasonable compared with the suggested value ranging from $76 \mathrm{~kJ} / \mathrm{mol}$ to $120 \mathrm{~kJ} /$ mol [20]. Therefore, equation (9) is rewritten as

$$
k=A \cdot \exp \left(-\frac{102000 \pm 6000}{R(T+273)}\right) \text {. }
$$

\subsection{Relationship between Mechanical Properties and Reaction} Kinetics. Equations (7) and (10) present the changing elastic modulus over aging time at $120^{\circ} \mathrm{C}$ and the reaction rate over temperatures, respectively. Equation (8), a bridge to connect the aging temperature and mechanical properties, presents the changing DP over aging time and reaction rate. 
Substitute the aging time in (7) with (8) and (10); then, a thermal-mechanical model is established to demonstrate the mechanical properties of aging pressboards. The expression of the model is

$$
E=\left(K_{1} \times e^{\left(1 / K_{2} k_{120}\right) k t}+K_{3}\right) \times \varepsilon^{\left(\left(K_{4} / k_{120}\right) k t+K_{5}\right)},
$$

where $k_{120}$ and $k$ is the reaction rate at $120^{\circ} \mathrm{C}$ and temperature $T$, respectively. $K_{1}, K_{2}, K_{3}, K_{4}$, and $K_{5}$ are constants, whose values are shown in Table 3 . The unit of $t$ is hour. Through (11), the influence of aging on mechanical properties of pressboards under temperature is normalized to the mechanical properties of the aging pressboard under $120^{\circ} \mathrm{C}$. Therefore, the elastic modulus under different aging time periods and temperatures can be estimated through (11).

\section{Prediction of the Remaining Clamping Pressure}

According to (4), the clamping pressure $F$ is proportional to the elastic modulus of pressboards. Therefore, the remaining clamping pressure, the ratio between the clamping pressure after a certain period of aging and the initial clamping pressure, is

$$
F \%=\frac{F(t)}{F_{0}}=\frac{E(t)}{E_{0}},
$$

where $E(t)$ is the elastic modulus at time $t$ and $E_{0}$ is the initial value of elastic modulus.

Equation (12) demonstrates that the progressive loss of winding clamping pressure is proportional to the change in vertical lines in Figure 3. The detailed calculation can be achieved through the following three steps:

Step 1: use the stress-strain curve of new pressboards to calculate the initial strain

Step 2: calculate the reaction rate $k$ based on a choosing temperature through (10)

Step 3: estimate the elastic modulus of aging pressboards and the remaining clamping pressure through (11) and (12), respectively

An optimistic prediction ( $A$ is $2.41 \times 10^{7}, E_{a}$ is 102000 ) of the progressive loss of clamping pressure under different initial clamping pressures is shown in Figure 8. The dash lines, dot-dash lines, and solid lines are the change of clamping pressure under the initial clamping pressures 2.5 $\mathrm{MPa}$, 3.0 $\mathrm{MPa}$, and $3.5 \mathrm{MPa}$, respectively. It can be observed that the clamping pressure decreases linearly with the increasing time under $60^{\circ} \mathrm{C}$. The remaining value after 30 year service under $20^{\circ} \mathrm{C}, 30^{\circ} \mathrm{C}, 40^{\circ} \mathrm{C}, 50^{\circ} \mathrm{C}$, and $60^{\circ} \mathrm{C}$ is $99.54 \%, 98.18 \%, 93.55 \%, 80.12 \%$, and $51.59 \%$, respectively. The clamping pressure drops sharply at the early stage when the temperature is higher than $60^{\circ} \mathrm{C}$. The decreasing clamping pressure shows difference with different initial clamping pressures and the remaining clamping pressure at initial pressure $3.5 \mathrm{MPa}$ is higher than that at $2.5 \mathrm{MPa}$ and 3.0 $\mathrm{MPa}$.
TABLE 3: Value of variables in equation (11).

\begin{tabular}{lcc}
\hline Parameter & Value & Units \\
\hline$k_{120}$ & $2.6369 \times 10^{-6}$ & \\
$K_{1}$ & 314.84 & $\mathrm{MPa}$ \\
$K_{2}$ & 300 & \\
$K_{3}$ & 2094.34 & $\mathrm{MPa}$ \\
$K_{4}$ & $8.8529 \times 10^{-4}$ & \\
$K_{5}$ & 0.7132 & \\
\hline
\end{tabular}

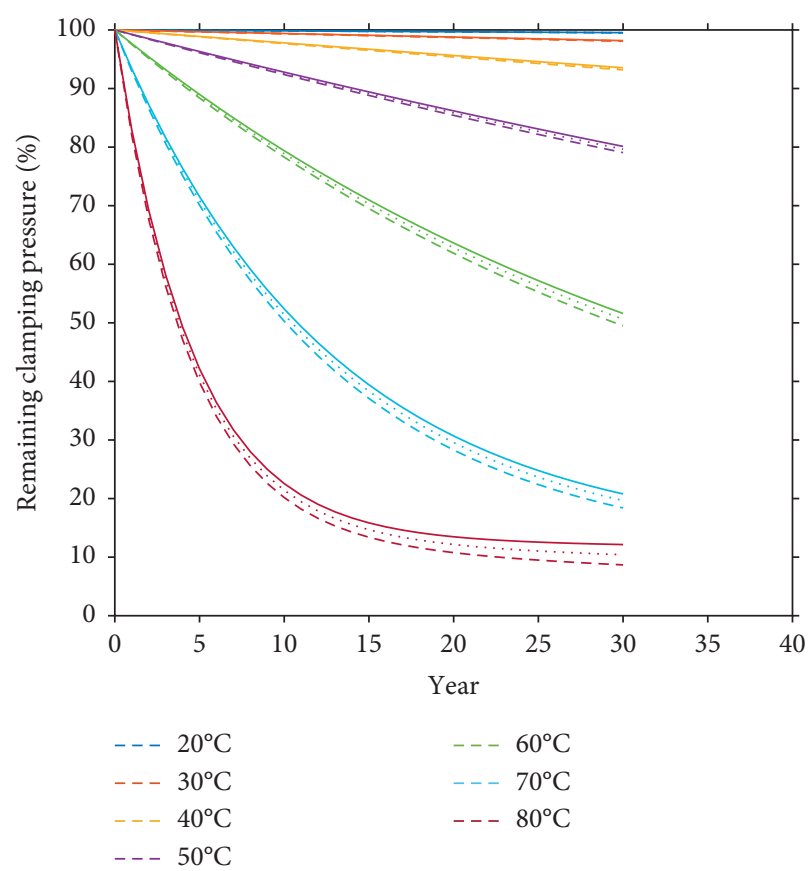

FIGURE 8: Prediction of the remaining clamping pressure versus operating temperature and time.

The obtained prediction is optimistic that the initial clamping pressure is set between $2.5 \mathrm{MPa}$ and $3.5 \mathrm{MPa}$ and the preexponential constant $A$ is only $2.41 \times 10^{7}$. Another important assumption is that all pressboards in windings have the same mechanical properties and aging degree. However, the aging degree of pressboards can be affected by the nonuniformly distributed oil temperature, and consequently, pressboards in different locations could have different aging degrees. In the future, it is more accurate to consider the difference in aging pressboards caused by the nonuniform temperature distribution in the prediction model.

\section{Conclusion}

This paper investigates the out-of-plane mechanical properties of aging pressboards and proposes a model to predict the progressive loss of winding clamping pressure. The clamping pressure decreases linearly with the increasing service life under low temperatures. When the temperature is higher than $60^{\circ} \mathrm{C}$, the clamping pressure shows a nonlinear drop with a significant decrease in the early stage. The remaining value after 30 -year service under $20^{\circ} \mathrm{C}, 30^{\circ} \mathrm{C}, 40^{\circ} \mathrm{C}$, 
$50^{\circ} \mathrm{C}$, and $60^{\circ} \mathrm{C}$ is $99.54 \%, 98.18 \%, 93.55 \%, 80.12 \%$, and $51.59 \%$, respectively. Future studies will focus on assessing the ability to withstand short circuits of transformer windings with different clamping pressures.

\section{Data Availability}

The data used to support the findings of this study are available from the corresponding author upon request.

\section{Conflicts of Interest}

The authors declare that there are no conflicts of interest regarding the manuscript.

\section{Acknowledgments}

This work was supported by the Science and Technology Project of State Grid Corporation of China under Grant no. 5204DY170010.

\section{References}

[1] S. V. Kulkarni and S. A. Khaparde, Transformer Engineering: Design, Technology, and Diagnostics, CRC Press, Boca Raton, FL, USA, 2016.

[2] T. Prevost, D. J. Woodcock, and C. Krause, "The effects on winding clamping pressure due to changes in moisture temperature and insulation age," in Proceedings of 66th International Conference of Doble Clients, pp. 27-31, Boston, MA, USA, 2000.

[3] Working Group A2.49, "Condition assessment of power transformers," CIGRE report, Reference 761, Cigre, Paris, France, 2019.

[4] T. A. Prevost and T. V. Oommen, "Cellulose insulation in oilfilled power transformers: part I - history and development," IEEE Electrical Insulation Magazine, vol. 22, no. 1, pp. 28-35, 2006.

[5] X. Zou, T. Uesaka, and N. Gurnagul, "Prediction of paper permanence by accelerated aging I. kinetic analysis of the aging process," Cellulose, vol. 3, no. 1, pp. 243-267, 1996.

[6] A. M. Emsley, R. J. Heywood, M. Ali, and C. M. Eley, "On the kinetics of degradation of cellulose," Cellulose, vol. 4, no. 1, pp. 1-5, 1997.

[7] A. M. Emsley, M. Ali, X. Xiao, and R. J. Heywood, "Degradation of cellulosic insulation in power transformers. part 4: effects of ageing on the tensile strength of paper," IEE Proceedings-Science, Measurement and Technology, vol. 147, no. 6, pp. 285-290, 2000.

[8] T. K. Saha, "Review of modern diagnostic techniques for assessing insulation condition in aged transformers," IEEE Transactions on Dielectrics and Electrical Insulation, vol. 10, no. 5, pp. 903-917, 2003.

[9] S. Y. Matharage, Q. Liu, and Z. D. Wang, “Aging assessment of kraft paper insulation through methanol in oil measurement," IEEE Transactions on Dielectrics and Electrical Insulation, vol. 23, no. 3, pp. 1589-1596, 2016.

[10] O. Girlanda, D. D. Tjahjanto, S. Östlund et al., "Characterization and modeling of the mechanical properties of pressboard," in Proceedings of the 2013 Annual Report Conference on Electrical Insulation and Dielectric Phenomena, pp. 563-566, Shenzhen, China, 2013.
[11] D. D. Tjahjanto, O. Girlanda, and S. Örland, "Anisotropic viscoelastic-viscoplastic continuum model for high-density cellulose-based materials," Journal of the Mechanics and Physics of Solids, vol. 84, pp. 1-20, 2015.

[12] N. Stenberg, "A model for the through-thickness elasticplastic behaviour of paper," International Journal of Solids and Structures, vol. 40, no. 26, pp. 7483-7498, 2003.

[13] L. Naranpanawe, C. Ekanayake, T. K. Saha, and P. K. Annamalai, "Influence of moisture dependency of pressboard on transformer winding clamping pressure," IEEE Transactions on Dielectrics and Electrical Insulation, vol. 24, no. 5, pp. 3191-3200, 2017.

[14] A. M. Emsley and G. C. Stevens, "Kinetics and mechanisms of the low-temperature degradation of cellulose," Cellulose, vol. 1, no. 1, pp. 26-56, 1994.

[15] O. Girlanda, K. Wei, T. Brattberg et al., "Influence of density on the out-of-plane mechanical properties of pressboard," in Proceedings of the 2012 Annual Report Conference on Electrical Insulation and Dielectric Phenomena, pp. 247-250, Montreal, Canada, October 2012.

[16] Baoding Tianwei Baobian Electric Co., Ltd., Manufacturing Process of Transformer, China Electric Power Press, Beijing, China, 2011.

[17] J. Borch, Handbook of Physical Testing of Paper, Marcel Dekker, New York, NY, USA, 2001.

[18] G. B. Watts, "A mathematical treatment of the dynamic behaviour of a power-transformer winding under axial shortcircuit forces," Proceedings of the Institution of Electrical Engineers, vol. 110, no. 3, pp. 551-560, 1963.

[19] Y. Hori and K. Okuyama, "Axial vibration analysis of transformer windings under short circuit conditions," IEEE Transactions on Power Apparatus and Systems, vol. PAS-99, no. 2, pp. 443-451, 1980.

[20] A. M. Emsley and G. C. Stevens, "Review of chemical indicators of degradation of cellulosic electrical paper insulation in oil-filled transformers," IEE Proceedings-Science, Measurement and Technology, vol. 141, no. 5, pp. 324-334, 1994.

[21] IEC 60450, Measurement of the Average Viscometric Degree of Polymerization of New and Aged Cellulosic Electrically Insulating Materials, International Electrotechnical Commission, Geneva, Switzerland, 2004. 